\title{
Publicidad de votos, concurrencias y disidencias en las sentencias del Tribunal Constitucional chileno: un análisis crítico
}

\author{
Publicity of Votes and Dissenting and Concurring Opinions \\ in the Chilean Constitutional Court: A critical review
}

\section{Edison Patricio Orellana Ramos (iD) \\ Abogado, Chile}

\begin{abstract}
RESUMEN La regulación sobre el modo en que el Tribunal Constitucional chileno toma sus decisiones, es decir, las reglas jurídicas acerca de cómo las sentencias deben ser producidas, implica que los miembros de dicho tribunal están obligados a votar acerca de la parte resolutiva de la sentencia y de sus fundamentos; que sus votos, disidencias y concurrencias deben expresarse en las sentencias, y que dichas disidencias y concurrencias deben expresarse nominalmente, indicando los nombres de quiénes concurren a la opinión mayoritaria y minoritaria. A partir de un concepto de legitimidad de los tribunales constitucionales basado en la independencia y neutralidad de los mismos en el contexto de una democracia constitucional, se ofrece un análisis crítico de los efectos que estas tres reglas combinadas producen, en cuanto afectan la legitimidad del Tribunal Constitucional chileno a través de la creación de incentivos hacia una excesiva personalización de sus decisiones y la defensa de posiciones extremas por parte de sus miembros.
\end{abstract}

PALABRAS CLAVE Tribunal Constitucional, legitimidad, votos disidentes, publicidad.

ABSTRACT The legal regulation concerning how the Chilean Constitutional Court make its decisions, that is, the legal rules about how the court's rulings have to be produced, imply that its members: 1) have to vote about the resolutive part of the opinion and its justification; 2) must express their votes and their concurring and dissenting opinions; and 3 ) that such votes, and concurring and dissenting opinions have to be nominal, that is, that the names of the opinions' authors are public. Starting from a concept of legitimacy of Constitutional Courts based on their independence and neutrality in the context of a constitutional democracy, I offer a critical review of the effects produced by the aforementioned rules since they affect the Chilean Constitutional Court's legitimacy through the creation of incentives which lead to an excessive «personalization» of its decisions and to the defense of extreme viewpoints by the judges. 
KEYWORDS Constitutional courts, legitimacy, dissenting opinions, publicity.

\section{Introducción}

Un aspecto que hasta ahora ha sido relativamente poco estudiado ( $y$, hasta ahora, rara vez cuestionado) respecto del Tribunal Constitucional chileno es el procedimiento que éste sigue para producir sus sentencias.

Pero ¿ cómo toma sus decisiones un tribunal constitucional? La respuesta a esta pregunta es en parte jurídica, ya que se trata de procesos regulados con variados niveles de especificidad, y en parte empírica, en lo que se refiere a las prácticas y convenciones que los jueces de un tribunal constitucional siguen, por ejemplo, en la deliberación secreta previa a la dictación de una sentencia o en las interacciones entre el redactor de la sentencia y los demás jueces. ${ }^{1}$ En esta última dimensión, nos encontramos en un terreno especulativo, ya que salvo para algunas de las personas que trabajan o han trabajado en un tribunal constitucional (con certeza, los jueces y sus asistentes), dichas prácticas y convenciones son desconocidas, con la notable excepción del Tribunal Constitucional de Italia, que en su página web publica una descripción detallada del procedimiento formal e informal para tomar una decisión. ${ }^{2}$

En el caso chileno, el procedimiento de creación de una sentencia del Tribunal Constitucional se encuentra regulado en la Constitución, en la Ley 17.977, más conocida como Ley Orgánica Constitucional del Tribunal Constitucional, en los autos acordados del Tribunal, y, por la vía de la remisión, en las normas del párrafo 2 del título $\mathrm{V}$ del Código Orgánico de Tribunales, que regula los acuerdos en las cortes de apelaciones, y en el artículo 170 del Código de Procedimiento Civil, que enumera las menciones que debe tener la sentencia definitiva de una causa. No obstante, hay un aspecto de esta regulación que hasta ahora no ha recibido suficiente atención y cuyo impacto se ha pasado por alto. Estas son las normas referidas a la publicidad de votos disidentes y concurrentes en las sentencias del Tribunal Constitucional. ${ }^{3}$

Las reglas específicas que regulan estos aspectos son, por una parte, la Ley 17.997 de 1981, artículo 17, inciso 1, donde se indica que:

\footnotetext{
1. Una buena forma de resumir la dimensión empírica del procedimiento para dictar una sentencia es la siguiente pregunta: ¿Qué pasa detrás de las «puertas cerradas» de un tribunal constitucional? Considerando que las reglas jurídicas que regulan dicho procedimiento son públicas, resulta de especial interés conocer las prácticas y convenciones de los tribunales en relación con su procedimiento de toma de decisiones, es decir, lo que ocurre «tras bambalinas» previo a la dictación de una sentencia.

2. «The Italian Constitutional Court», Corte Constituzionale, 28 de marzo de 2012, pp. 40-51, disponible en https://bit.ly/2JqoqRp.

3. Una excepción parcial a esto puede encontrarse en Verdugo (2011). Es parcial porque este artículo se enfoca en los tipos de voto disidente (público/secreto) en tribunales colegiados en general, y no en los tribunales constitucionales en particular. Para un estudio sobre los votos individuales de cada ministro del Tribunal Constitucional chileno entre 1990 y 2010, véase Carroll y Tiede (2011).
} 
Los acuerdos del tribunal se regirán, en lo pertinente, por las normas del párrafo 2 del título V del Código Orgánico de Tribunales, en lo que no sean contrarias a las de esta ley y los votos se emitirán en orden inverso a la precedencia establecida en al artículo 6. El último voto será el del presidente. ${ }^{4}$

Posteriormente, la misma ley señala en su artículo 31, inciso 2, que «los ministros que discrepen de la opinión mayoritaria del tribunal deberán hacer constar en el fallo su disidencia». Por otro lado, el Código Orgánico de Tribunales de 1943 indica en su artículo 89, inciso 1, que «en los autos y sentencias definitivas e interlocutorias de los tribunales colegiados, se expresará nominalmente qué miembros han concurrido con su voto a formar sentencia y qué miembros han sostenido opinión contraria, lo que quedará registrado electrónicamente».

En resumen, al momento de dictar una sentencia los ministros del Tribunal Constitucional están obligados a votar acerca de la parte resolutiva de la sentencia y de sus fundamentos; a que sus votos, concurrencias y disidencias deban expresarse en las sentencias; y que dichas concurrencias y disidencias deban expresarse nominalmente, es decir, indicando los nombres de quiénes concurren a la opinión mayoritaria y minoritaria.

Como puede apreciarse, estas reglas consagran un sistema en que el resultado final de una decisión del tribunal es completamente público y transparente, de manera semejante a lo que ocurre en la Corte Suprema de los Estados Unidos de América, en que sólo la deliberación previa a la sentencia es secreta, en contraste con los modelos de tribunales constitucionales de la Europa Continental, que suelen mantener en secreto el resultado de la votación. ${ }^{5}$ En este contexto, la tesis que defenderé en este trabajo es que estas tres reglas - que, en síntesis, apuntan a la publicidad y nominalidad de votos, concurrencias y disidencias $-{ }^{6}$ producen efectos que en su conjunto afectan la neutralidad que un tribunal constitucional debería tener, y consecuentemente su legitimidad en el contexto de una democracia constitucional. Es muy posible que, hasta ahora, la importancia de dichas reglas y su impacto en la legitimidad del Tribunal Constitucional hayan pasado inadvertidas por el hecho de que esta regulación es muy similar a

4. En lo sucesivo, cada vez que se incluyan cursivas en una cita será por decisión del autor con el objetivo de destacar algún fragmento.

5. Para un contraste entre los niveles de transparencia de los procedimientos de votación en la Corte Suprema de los Estados Unidos de América y los tribunales constitucionales de Europa continental, véase Kelemen (2013: 1.362-1.363). Allí se distinguen tres grados de transparencia dentro de la etapa de dictación de la sentencia. El primer grado de transparencia permite a los jueces publicar sus disidencias. El segundo grado de transparencia es la posibilidad de publicar el número de votos a favor y en contra de la decisión. Por último, con el tercer grado de transparencia el voto de cada juez es público, ya sea que decida o no escribir un voto disidente.

6. Es pertinente aclarar que mi objeción no incluye al uso de las normas del párrafo segundo del Título V del Código Orgánico de Tribunales por parte del Tribunal Constitucional, salvo en lo que se refiere al carácter nominal de los votos. Debo esta observación a un evaluador anónimo. 
la que rige las decisiones y sentencias de otros tribunales colegiados, particularmente aquellos que pertenecen al Poder Judicial. Sin embargo, es un hecho que la jurisdicción constitucional, en cuanto actividad, tiene relevantes diferencias con la jurisdicción legal u ordinaria, por lo que tiene sentido al menos preguntarse por otras opciones de regulación de esta materia. ${ }^{7}$

En este contexto, el presente trabajo se divide en cuatro secciones. En la primera explico la noción de «legitimidad» a la que me referiré y a su aplicación específica a los tribunales constitucionales de las democracias liberales. En la segunda sección presento y desarrollo mis argumentos en contra de la publicidad de votos, disidencias y concurrencias en las sentencias del Tribunal Constitucional chileno. Finalmente, en la tercera sección enuncio los lineamientos generales para reformas legales sobre dicha materia que permitan fortalecer la independencia y neutralidad del tribunal.

\section{Legitimidad y tribunales constitucionales}

El término «legitimidad» admite distintos usos y, en virtud de eso, es necesario aclarar cuál consideraré para este trabajo. En primer lugar, es importante aclarar que con «legitimidad» de una institución o autoridad no me referiré a su «eficacia» (es decir, el simple hecho de que una institución funcione y que sus decisiones sean generalmente obedecidas), ni a su «legalidad» (o «validez» en sentido kelseniano), ${ }^{8}$ ya que tal como señala Kemelen «dado que los Tribunales Constitucionales [en contraste con la Corte Suprema de los Estados Unidos de América] están explícitamente dotados con el poder para realizar el control de constitucionalidad por sus respectivas constituciones nacionales, el tópico de la legitimidad de estos Tribunales no puede tener un carácter "formal" (Kemelen, 2013: 1357). Tampoco es el objeto central de este trabajo la aprobación social o popularidad («legitimidad» en sentido empírico) de los Tribunales Constitucionales. Para propósitos de este trabajo, con «legitimidad» me referiré a «las razones/argumentos racionales que podrían apoyar la existencia de una institución como el Tribunal Constitucional» (Pasquino, 2018: 201).

En otros términos, en el contexto de este trabajo «legitimidad» se refiere a las posibles respuestas a la siguiente pregunta: ¿por qué debería existir un tribunal constitucional? Se trata, entonces, de preguntarnos si una Constitución debería o no darle a una

7. Una diferencia mencionada frecuentemente entre la jurisdicción constitucional y la jurisdicción ordinaria o legal es la naturaleza del lenguaje de la Constitución, particularmente en la regulación de los derechos constitucionales, que suele usar conceptos generales cuyo contenido es parcialmente indeterminado como «igualdad», «libertad» o «bien común», lo cual deja al intérprete de las reglas de la Constitución con un grado mayor de discreción que el que tiene un intérprete de una ley ordinaria. Para una crítica de esta posición, véase Atria (2016: 267 y ss.)

8. Hans Kelsen define validez como «la existencia específica de una norma», esto es, que una norma tiene fuerza obligatoria para aquellos cuyo comportamiento regula. Para una explicación del rol de la idea de «validez» en su teoría del derecho (y en particular de la idea de «cadena de validez»), véase Kelsen (1949: 110 y ss.; 2008: 193 y ss.). 
institución cuyos miembros no son elegidos por la ciudadanía el poder de controlar la constitucionalidad de la legislación, y en este sentido esta noción de legitimidad es «meta-constitucional porque la objeción está dirigida al constituyente y no a los jueces constitucionales» (Kemelen, 2013: 1358). En consecuencia, no me referiré aquí a las objeciones de legitimidad dirigidas a los jueces constitucionales sobre la base de exceder los límites impuestos por la Constitución (lo que se conoce habitualmente como «activismo judicial»).

Adicionalmente, por razones metodológicas es pertinente mencionar la distinción entre legitimidad «de entrada» (input legitimacy) y legitimidad «de salida» (output legitimacy). ${ }^{9}$ La legitimidad de entrada se refiere a la forma en que los tribunales son diseñados (el procedimiento de selección de sus integrantes y su composición), mientras que la legitimidad de salida se refiere su proceso de toma de decisiones [decisionmaking] y su impacto en el sistema legal y en la sociedad. En consecuencia, atendido el objeto de este trabajo (la publicidad de votos, disidencias y concurrencias en las sentencias del Tribunal Constitucional), la legitimidad a la que me referiré será principalmente la legitimidad «de salida».

Hechas estas aclaraciones conceptuales, cabe preguntarse por las posibles relaciones existentes entre los distintos usos del término «legitimidad». Para efectos de este trabajo, me interesa particularmente la relación entre «legitimidad» y aprobación social (o legitimidad empírica). En efecto, parece razonable creer que el hecho de formular más y mejores razones que apoyen la existencia de un tribunal constitucional puede contribuir a que esta institución goce de una mayor aprobación en la ciudadanía. ${ }^{10}$

En una democracia constitucional la principal fuente de «legitimidad» (en el sentido ya especificado) de las autoridades públicas son las elecciones. Sin embargo, es importante tener en cuenta que las principales teorías clásicas sobre la democracia del siglo XX (Sartori, Schumpeter, Kelsen) no abordan la legitimidad de los tribunales constitucionales o, más específicamente, la del control judicial de constitucionalidad de las leyes en una democracia constitucional. ${ }^{11}$ No obstante:

La pregunta sobre la legitimidad de los tribunales constitucionales es cualquier cosa menos nueva: fue discutida no solo en los Estados Unidos de América en el siglo XIX, sino también con una extraordinaria riqueza de argumentos y contrargumentos por profesores de derecho durante la República de Weimar, ${ }^{12}$ y por actores políticos en Italia durante el proceso de creación de la Constitución republicana en Roma en 1946-

9. Distinción introducida por Wocjciech Saurski, citado en Kemelen (2013: 1.358; nota al pie).

10. Es digno de atención el hecho de que en Chile no existen encuestas que midan la confianza ciudadana en el Tribunal Constitucional. Dentro de las encuestas que miden confianza ciudadana en instituciones, solo se incluye genéricamente a los «tribunales de justicia» y en casos excepcionales a la Corte Suprema.

11. Un caso excepcional es el de Francia, donde el Consejo Constitucional es concebido como un órgano político y no como un tribunal, por lo cual el control de constitucionalidad no sería judicial.

12. Particularmente ilustrativo es el debate entre Hans Kelsen y Carl Schmitt. Al respecto, véase Vinx (2015) y Kelsen y Schmitt (2009). 
47, cuando la institución de un tribunal constitucional tuvo una fuerte oposición de los miembros comunistas y socialistas de la Asamblea Constituyente (Pasquino, 2018: 201).

Pero ¿son las elecciones la única fuente de legitimidad de la autoridad en una democracia constitucional? Una primera alternativa teórica para abordar el tema de la legitimidad de los tribunales constitucionales sería utilizar las elecciones como procedimiento de designación de los miembros de los tribunales constitucionales, de modo que su poder derivara directamente de la ciudadanía. Sin embargo, no es este el camino que voy a seguir en el presente trabajo. Ello, principalmente por tres razones:

- Porque a pesar de que este es un caso de teoría normativa, no puede desconocerse que, en los hechos, en ningún Tribunal Constitucional o Corte Suprema del mundo se designa a sus miembros a través de elecciones (con la excepción calificada del Tribunal Constitucional Plurinacional de Bolivia).

- Porque un tribunal constitucional elegido por la ciudadanía sería prácticamente idéntico a un Congreso (salvo en el número de sus miembros), por lo que sería innecesario e ineficiente tener un tribunal constitucional en esas circunstancias.

- Porque uno de los objetivos de la jurisdicción constitucional es precisamente proteger los derechos constitucionales de todos, pero especialmente de la minoría que pierde las elecciones (esta es, de acuerdo a Kelsen, la justificación política de la existencia de un tribunal constitucional), ${ }^{13}$ lo cual no tendría garantías de ocurrir si los miembros del tribunal fueran designados por la mayoría electoral. ${ }^{14}$

Entonces, la pregunta sobre la legitimidad de un tribunal constitucional subsiste. Si no ha de basarse en que sus miembros son elegidos por la ciudadanía, ¿cuál podría ser el fundamento de su legitimidad en el contexto de una democracia constitucional?

Como es sabido, uno de los fundamentos de la democracia constitucional es el principio de separación de los poderes, y a su vez la finalidad de la separación de los poderes es evitar el despotismo, esto es, el poder ilimitado. Para Montesquieu, el despotismo existe no sólo cuando los tres poderes del Estado concurren en una misma persona o institución, sino también cuando un órgano tiene el monopolio para el ejercicio de la función legislativa (la función de crear normas obligatorias para todos). Sin embargo, en la actualidad las democracias constitucionales dividen la función normativa de

13. La justificación política de la existencia de un tribunal constitucional (esto es, la que apela a la protección de los derechos de la ciudadanía y en particular, de la parte de la ciudadanía que apoyó a los partidos que perdieron las elecciones) es apenas mencionada por Hans Kelsen, quien no la desarrolló en sus escritos.

14. Sobre designaciones por simple mayoría de miembros de Tribunales que ejercen el control de constitucionalidad, es pertinente mencionar que, desde abril de 2017, los miembros de la Corte Suprema de los Estados Unidos de América pueden ser designados por simple mayoría del Senado, dado que fue eliminada la posibilidad de usar el mecanismo del filibuster, que podía evitar la votación de una nominación si no se contaba con $3 / 5$ de senadores que la apoyaran. 
efectos generales entre autoridades elegidas (Congreso y Presidente de la República) y no elegidas (Banco Central, Tribunal Constitucional, órganos de la Administración del Estado). La razón de esta división del poder es la posibilidad de que las autoridades electas puedan violar los derechos individuales de los ciudadanos. El problema es que tales derechos, que operan un límite al poder de la mayoría, tienen un contenido parcialmente indeterminado, por lo que los conflictos de interpretación sobre dicho contenido son inevitables. En este contexto ¿cómo resolvemos dichos conflictos? Es aquí donde la existencia de un Tribunal Constitucional se hace necesaria, para que un tercero imparcial y ante todo independiente pueda procesar institucionalmente los conflictos sobre el contenido de los derechos constitucionales que necesariamente van a tener lugar en cualquier régimen democrático. Desde luego, esto no significa que cualquier tribunal constitucional, por el sólo hecho de existir, es inevitablemente legítimo. Pero entonces, ¿qué parámetro podemos usar para juzgar su legitimidad?

En este contexto, defenderé aquí que para ser legítimos en el contexto de un régimen de democracia liberal los tribunales constitucionales deben tener al menos dos cualidades: independencia y neutralidad. ${ }^{15}$ La novedad aquí no es el uso de tales conceptos como fundamento de legitimidad de una institución, sino el entendimiento que usaré de los mismos (particularmente de la neutralidad):

Por independencia quiero significar simplemente que los jueces constitucionales, al no ser controlables por el gobierno o los ciudadanos (su período no es renovable como ocurre en la mayoría de los casos), deben contar con la precondición esencial de la neutralidad: los magistrados no dependen de los intereses de las partes involucradas en los conflictos constitucionales que deben resolver. Por la expresión «neutralidad» no quiero señalar que debe existir objetividad absolutamente perfecta (esta definición únicamente encajaría en la versión teológica del concepto), sino, más bien, hago referencia a la calidad de las decisiones que son el resultado del compromiso de preferencias diferentes y balanceadas. Esto solo puede lograrse, al menos de forma aproximada, bajo ciertas condiciones relativas a la elección de los miembros de las cortes, así como al protocolo que se usa para decidir (Pasquino, 2016: 37; énfasis nuestro).

Pero ¿por qué independencia y neutralidad? Porque en el caso de un tribunal constitucional, en el contexto de la separación de poderes de una democracia constitucional contemporánea recientemente descrito, su legitimidad no puede tener el mismo origen que el órgano que crea las leyes cuya constitucionalidad ha de ser controlada por el Tribunal (Congreso/Parlamento), para poder tener así un contrapeso efectivo entre las autoridades electas y no electas que participan de la función legislativa. En este contexto, la legitimidad de un tribunal constitucional debe definirse en oposición a la legitimidad del Congreso/Parlamento (lo cual concuerda con el rol de legislador

15. Para una respuesta alternativa al problema de la legitimidad de los tribunales constitucionales en relación con los votos disidentes en las sentencias, que enfatiza los principios de independencia judicial y toma de decisiones transparente, véase Kemelen (2013: 1357 y ss.). 
negativo que Kelsen le atribuye a los tribunales constitucionales). ${ }^{16}$ Así, mientras los miembros del Congreso deben ser dependientes de la ciudadanía y partidistas (porque necesitan ganar elecciones para acceder a sus cargos y mantenerse en ellos), los tribunales constitucionales deben ser independientes y neutrales. ${ }^{17}$ En definitiva, con el fin de fortalecer la legitimidad del tribunal constitucional debiera evitarse a toda costa que dicha institución se convierta, en la teoría y en la práctica, en un microparlamento o Congreso a escala. ${ }^{18}$

En este contexto, la legitimidad de un tribunal constitucional, es decir, su independencia y neutralidad, dependería de

- el procedimiento de designación de sus miembros;

- y del procedimiento utilizado para tomar sus decisiones (que incluye todo lo que ocurre una vez que un asunto que está siendo conocido por el tribunal queda en estado de ser resuelto por el mismo, hasta la dictación y notificación de la sentencia a las partes).

Es en este último punto donde se conecta la legitimidad de un tribunal constitucional con las normas referidas a la publicidad de votos, de disidencias y de concurrencias en las sentencias del Tribunal Constitucional chileno.

En concreto, sostendré aquí es que en el caso chileno lo que dichas normas afectan, en cuanto reguladoras del proceso de toma de decisiones, es la neutralidad del Tribunal. En otras palabras, la posición que defenderé es que la mencionada normativa hace improbable que las sentencias del Tribunal Constitucional sean el resultado del compromiso de preferencias diferentes y balanceadas, al incentivar el personalismo y no la búsqueda de acuerdos entre los ministros.

Antes de presentar mi argumentación en contra de la actual regulación sobre publicidad de votos, disidencias y concurrencias en las sentencias del Tribunal Constitucio-

16. La posición contraria, es decir, que el órgano que ejerce el control de constitucionalidad de las leyes debe tener la misma fuente de legitimidad (las elecciones) que el órgano que crea las leyes, fue defendida célebremente por Carl Schmitt, quien sostenía que el control de constitucionalidad debía realizarlo una autoridad elegida directamente por los ciudadanos, a saber, el presidente del Reich, quien en contraste con el Parlamento sería un poder neutral. Al respecto, véase Kelsen y Schmitt (2009: 239 y ss.).

17. Esta perspectiva muestra parcialmente los eventuales peligros de un tribunal constitucional que en sus prácticas imita al Congreso, como ocurrió, por ejemplo, con el Tribunal Constitucional chileno en 2017 durante la tramitación del requerimiento de inconstitucionalidad respecto a normas del proyecto de ley que regula la despenalización de la interrupción voluntaria del embarazo en tres causales. En dicha ocasión, el tribunal autorizó, basado en el artículo 37 de la Ley Orgánica Constitucional del Tribunal Constitucional, la realización de audiencias públicas durante dos días para oír a diversas personas y organizaciones de la sociedad civil, de un modo análogo a las audiencias que se realizan en las comisiones del Congreso Nacional.

18. Con todo, hay una diferencia fundamental entre el Congreso y el Tribunal Constitucional relativa al tipo de voto. Mientras los miembros del Tribunal Constitucional están obligados a justificar sus decisiones (lo que por regla general se traduce en la obligación de justificar sus votos en las sentencias), los miembros del Congreso no tienen dicha obligación. 
nal chileno, considero necesario mencionar que tanto el procedimiento de designación de los miembros de un tribunal constitucional como el procedimiento para dictar una sentencia tienen un aspecto teórico (o normativo), y uno práctico (o consuetudinario). Ambos procedimientos tienen aspectos regulados por normas legales o constitucionales, pero también incluyen prácticas o convenciones no escritas que tienen lugar especialmente durante la deliberación secreta y las interacciones entre el redactor de la sentencia y los demás jueces. Esto implica que cualquier investigación acerca de la legitimidad de un tribunal constitucional no solo requiere indagar en las normas jurídicas aplicables a ellos, sino también en la práctica efectiva que realizan sus miembros (cuando se trata del procedimiento de toma de decisiones del tribunal) como asimismo las prácticas de los actores involucrados en el procedimiento de designación de un miembro del tribunal.

\section{Publicidad y nominalidad de votos en los tribunales constitucionales}

Ahora estoy en condiciones de presentar argumentos en contra de la actual regulación sobre publicidad de votos, disidencias y concurrencias en las sentencias del Tribunal Constitucional chileno. ${ }^{19}$ Debo aclarar que mi argumento es sobre la publicidad y nominalidad de votos disidentes y concurrentes, y no sobre su existencia. En efecto, es perfectamente posible que los miembros de un tribunal colegiado voten de manera dividida, de modo que exista una mayoría y una minoría cuyos razonamientos puedan ser conocidos por la ciudadanía, pero sin que se indique quiénes concurrieron a la mayoría y quiénes a la minoría (esto es conocido como el «disenso anónimo»).

En primer término, es importante tener presente que la publicidad de votos, disidencias y concurrencias en las sentencias de tribunales colegiados cuyas decisiones no son revisables (típicamente cortes supremas y tribunales constitucionales) es la regla general en los países del common law. Sin embargo, en países como Italia y Francia la publicidad de los de votos concurrentes y disidentes en las sentencias está prohibida, de modo que el tribunal habla con una sola voz. En consecuencia, «el público no sabe si el voto fue unánime o dividido, ni cómo votó cada miembro del tribunal» (Pasquino, 2015: 198). No obstante, en sus deliberaciones los miembros del tribunal votan abiertamente entre ellos. Además, se debe tener presente que:

La deliberación "cara a cara» en la Corte italiana está mucho más desarrollada, particularmente en todos los casos difíciles e importantes. En un texto que se puede

19. El Tribunal Constitucional de Italia, en un documento disponible en su página web, enumera razones en contra de la publicidad de los votos de los miembros de un tribunal constitucional. En particular, señala que la publicidad de los votos disidentes: 1) implica una excesiva personalización de las decisiones del Tribunal Constitucional; 2) expone a los jueces a presiones externas; 3) debilita la autoridad de las decisiones de la Corte; y 4) produce un reducido incentivo para los jueces para buscar el más amplio consenso posible para las decisiones del Tribunal. Estos argumentos son analizados en esta sección a la luz del concepto de legitimidad analizado previamente. 
consultar en su página web, la Corte ha descrito claramente el procedimiento formal e informal para arribar a una decisión. Este busca, principalmente, una decisión consensuada entre los miembros de la Corte como órgano colegiado. La ausencia de salvamentos y aclaraciones de voto -siguiendo la tradición francesa de una corte que habla con una sola voz- representa un incentivo para encontrar una postura intermedia entre las posiciones divergentes en aquellos casos de desacuerdo entre los magistrados. La ausencia de limitantes temporales para decidir permite la posibilidad de deliberar para lograr un acuerdo, teniendo en cuenta que el mismo problema puede ser discutido en más de una reunión, lo cual es habitual para cualquier decisión importante (Pasquino, 2016: 33).

Adicionalmente, en lo que respecta al Tribunal Constitucional Federal de Alemania, la publicidad de votos concurrentes y disidentes no está prohibida en las sentencias, aunque fue introducida solo a partir de 1971. No obstante, entre 1971 y 2012, solo el 7 $\%$ de las sentencias publicadas tenían algún voto disidente (Pasquino, 2016: 24, nota al pie). En efecto, «la deliberación de la Corte tiene como función -y es proclive a- lograr un acuerdo entre los magistrados, lo cual explica el número tan limitado de disidencias (sondervotum)» (Pasquino, 2016: 36). Adicionalmente, merece la pena mencionar que después de la reforma de 1971 el Tribunal tiene la posibilidad publicar el número de votos a favor y en contra de la solicitud planteada ante él, pero sólo de forma anónima (esto es, sin indicar los nombres de los jueces que votaron) (Kelemen, 2013: 1.348).

Para continuar con el análisis es pertinente introducir dos distinciones conceptuales. Una relativa a los tipos de voto que pueden tener lugar en un cuerpo colegiado, y otra referida a una clasificación de tribunales basada en el tipo de voto que utilizan en los procedimientos para tomar sus decisiones. La primera distinción (Pasquino, 2015: 196) es entre voto nominal (disclosed vote); voto anónimo (undisclosed vote); y voto secreto (secret vote).

Esta distinción intenta cubrir todas las opciones posibles de voto en órganos colegiados, en contraste con la usual distinción entre voto público y voto secreto. En efecto, hay que distinguir la publicidad del voto según si esta se refiere al público en general o a los demás miembros del órgano colegiado. Así las cosas, un voto en particular puede ser desconocido para el público en general, pero conocido o desconocido para los demás miembros del órgano colegiado.

La segunda distinción es entre tribunales colegiales (collegial courts) y tribunales plurales (pluralistic courts). Es una clasificación de los tribunales basada en el tipo de voto que emplean (en este caso, si es anónimo o nominal) y que adoptan para tomar sus decisiones.

La forma más sencilla de explicar esta dicotomía es la afirmación según la cual es importante distinguir aquellas cortes que hablan con una sola voz (gracias al carácter reservado de los votos de sus miembros), de aquellos tribunales en los que los magistrados tienen una clara personalidad pública, y quienes tratan de «enseñar desde la magistratura», refiriéndose a individuos específicos del público externo por medio 
de las opiniones disidentes (o salvamentos de voto), o concurrentes (aclaraciones de voto) (Pasquino, 2016: 23-24).

En resumen, los tribunales que tienen voto anónimo son colegiales, mientras que los que tienen voto nominal son plurales.

Uno podría argumentar que en realidad esta última distinción, siendo conceptualmente útil, en la práctica es artificial dado que tanto en tribunales colegiales como en tribunales plurales sus miembros votan para adoptar una decisión y usan una regla de mayoría. Sin embargo, es necesario tener en cuenta el rol y el efecto de los procedimientos que, en los hechos, son bastante diferentes según si se trata de un tribunal con voto anónimo o de un tribunal con voto nominal.

Una consecuencia relevante de la distinción entre tribunales colegiales y tribunales plurales es que los primeros «son generalmente percibidos por el público como cuerpos anónimos en lugar de grupos pequeños de individuos bien conocidos con considerables perfiles públicos y personalidades» (Pasquino, 2015: 206). En cambio, en los países en que hay tribunales plurales, como en los Estados Unidos de América, los jueces son verdaderas celebridades.

Otra consecuencia importante tiene que ver con que un tribunal colegial, por tener un sistema de voto anónimo, se parece menos a un microparlamento o Congreso a escala. Como es sabido, los votos de los miembros del Congreso son públicos, porque actúan en representación de terceros que los eligieron y ante los cuales son responsables. En otras palabras, la publicidad del voto de los miembros del Congreso sirve para que los electores puedan evaluar la gestión de los parlamentarios y actuar en consecuencia en la siguiente elección. Todo esto no debería ocurrir en el caso de un tribunal constitucional, y el voto anónimo es un mecanismo adecuado para ese propósito. En efecto, tratándose de jueces de tribunales constitucionales con voto anónimo, «sus sentencias no tendrán impacto en la renovación de sus cargos (que es imposible) o en otros posibles nombramientos al final de sus períodos» (Pasquino, 2018, 214). Esto es particularmente importante para los casos en que un juez del Tribunal Constitucional puede ser designado directamente por el presidente de la República sin necesidad de confirmación por parte de otro(s) órgano(s) (como ocurre en Chile con tres de los diez ministros del Tribunal Constitucional), ya que la publicidad de votos, disidencias y concurrencias permite al presidente "fiscalizar" el comportamiento del juez designado con miras a futuros nombramientos (no necesariamente en el gobierno), lo que evidentemente afecta la independencia de dicho juez.

Además, si observamos cómo operan los tribunales constitucionales de cada una de estas categorías, cada tipo de tribunal de la mencionada distinción tribunales colegiales/tribunales plurales tiene su propio criterio determinante para alcanzar una decisión final respecto de un caso. En los tribunales colegiales los criterios suelen ser los argumentos que se ofrecen en la deliberación previa a la dictación de la sentencia, mientras que en los tribunales plurales el criterio es el voto. Cada uno de estos criterios implica, desde luego, ventajas y desventajas. En el caso del voto, este mecanismo per- 
mite llegar rápidamente a una decisión final, lo que a su vez facilita el mejor manejo de la creciente carga de trabajo de los tribunales constitucionales. No obstante, el voto (nominal) desincentiva la deliberación en sentido estricto entre los ministros, es decir, la realización de sesiones de larga duración en que los jueces se reúnen a intercambiar y debatir argumentos sobre el caso en cuestión. Esta ausencia de deliberación en sentido estricto favorece la expresión de posiciones más extremas en las sentencias, particularmente entre jueces de origen académico, que tienen mayor tendencia a discrepar de sus colegas (es un hecho público y notorio que en la academia una de las características más valorada es la originalidad). En efecto, «bajo el voto nominal, los jueces tienen un incentivo a mantener una imagen pública consistente en lugar de buscar un acuerdo» (Pasquino, 2015: 203). En contraste, una deliberación en sentido estricto entre los jueces, particularmente cuando se cuenta con un plazo razonable para dictar la sentencia, incentiva la búsqueda de consensos y de posiciones intermedias. En este sentido:

Como el tribunal habla para las personas y a través de decisiones que son definitivas y no sujetas a apelación, parece prudente que la decisión final incorpore diferentes puntos de vista en lugar de la voluntad o las creencias de la mayoría, que, por cierto, no es la expresión de una mayoría popular y que no puede legítima o decentemente imponer su opinión sobre los jueces disidentes (Pasquino, 2015: 208).

No obstante, debe tener presente que llegar a una decisión a través de este mecanismo puede tomar mucho más tiempo y eso puede ser problemático, particularmente dada la creciente carga de trabajo de los tribunales constitucionales. ${ }^{20}$ Sin embargo, esto podría resolverse a través de la contratación de más personal de apoyo (en particular de más abogados asistentes para cada ministro del tribunal). ${ }^{21}$

Considerando el concepto de neutralidad mencionado previamente (referido a la calidad de decisiones que son el resultado del compromiso de preferencias diferentes y balanceadas) y su rol fundamental en la legitimidad de un Tribunal Constitucional, la balanza se inclina en favor de una deliberación en sentido estricto. En efecto, dicho procedimiento induce a la búsqueda de soluciones de consenso y, por lo mismo, es posible afirmar que las decisiones de un tribunal constitucional colegiado son comparativamente más neutras que las de un tribunal constitucional plural y, consecuentemente, un tribunal constitucional colegiado será más legítimo que un tribunal constitucional plural.

En el Tribunal Constitucional de Italia, probablemente el mejor ejemplo disponible de tribunal colegial, el voto anónimo tiene una importante consecuencia:

20. De acuerdo con las estadísticas disponibles en la página web del Tribunal Constitucional chileno, los asuntos ingresados para tramitación en los últimos tres años son las siguientes: 186 (2015); 357 (2016); 930 (2017). Estas cifras por sí solas muestran un aumento explosivo en la carga de trabajo.

21. En la actualidad cada uno de los diez ministros del Tribunal Constitucional cuenta con un abogado asistente, siendo este número de abogados asistentes fijado en la Ley Orgánica Constitucional del Tribunal Constitucional (Ley 17.997, 1981: artículos 74 y 75). Asimismo, de acuerdo con la información disponible en su página web, este cuenta con una Dirección de Estudios que apoya a los ministros y sus abogados asistentes en su trabajo. 
Si los disidentes son una minoría significativa y si ellos tienen argumentos constitucionales ostensiblemente serios, su desacuerdo no puede ser simplemente descartado y superado por votos como en un parlamento o un cuerpo políticamente responsable [accountable] donde la mayoría, bajo el escrutinio de los votantes, puede hacer pagar por su decisión en la siguiente elección. El presidente [del tribunal] puede pedir al juge rapporteur [juez redactor] tomar en cuenta la opinión de la minoría y tratar de integrarla en el borrador que será analizado repetidamente hasta que el tribunal logre alguna forma de acuerdo (Pasquino, 2015: 208).

En otras palabras, el Tribunal Constitucional italiano opera en la práctica, para efectos de la deliberación previa a la sentencia, de forma análoga a como operan los jurados en el common law, en el sentido en que ambos casos que la deliberación se prolonga hasta que exista un acuerdo entre los miembros del cuerpo colegiado (veredicto unánime en el caso de los jurados). Sin embargo, una diferencia relevante aquí es que mientras en las deliberaciones de jurados en la tradición del common law se exige continuidad en la deliberación (los miembros del jurado no pueden salir del lugar en que se han reunido hasta que se alcance un acuerdo), los miembros del Tribunal Constitucional de Italia pueden sesionar varias veces respecto de un mismo caso, sin que se exija continuidad.

Ahora bien, como ya se anticipó al inicio, los ministros del Tribunal Constitucional chileno están obligados a votar acerca de la parte resolutiva de la sentencia y de sus fundamentos; a que sus votos, concurrencias y disidencias deban expresarse en las sentencias; y que dichas disidencias y concurrencias deban expresarse nominalmente, es decir, indicando los nombres de quiénes concurren a la opinión mayoritaria y minoritaria.

En consecuencia, en el contexto de la distinción tribunales colegiados y tribunales plurales, el Tribunal Constitucional chileno sería un tribunal plural dada la publicidad obligatoria de los votos disidentes y concurrentes en sus sentencias.

En este escenario, la pregunta relevante es acerca del uso efectivo que los ministros del Tribunal Constitucional chileno dan a los votos concurrentes y disidentes. Sobre el particular, existe evidencia empírica que muestra que los ministros, cualquiera sea su origen profesional (judicial, académico o político) o la autoridad que los haya designado en el cargo, hacen un uso intensivo de concurrencias y disidencias desde el año 2006 a la fecha, comparado con lo que ocurrió en el período 1990-2005. En efecto, en 2015 un estudio advirtió una tendencia preocupante en las sentencias desde la reforma constitucional de 2005, en el sentido de evitar dictar sentencias de manera unánime, en contraste con lo que ocurría previo a dicha reforma (Pardow y Verdugo, 2015). En el mismo sentido, «la tasa de votos particulares entre agosto de 2006 y marzo de 2011 fue de un 49,9\% (263 sentencias presentaron votos separados de un total de 527)» (Verdugo, 2011: 264). A partir de estos datos, no es exagerado afirmar que desde la reforma constitucional del 2005 existe un creciente abuso de los votos particulares (concurrencias y disidencias) en el Tribunal Constitucional. 
En el contexto de una publicidad obligatoria de concurrencias y disidencias en las sentencias del tribunal, un uso prudente de las mismas no debería ser tan problemático. Sin embargo,

Lo que resulta ser contrario al espíritu de una corte neutral es el abuso de las disidencias. Una tentación constante a la cual el juez se debe resistir radica en usar el salvamento para dirigirse a un público externo a la Corte, en lugar de entablar un diálogo con los colegas con quienes tomará la decisión. El uso excesivo de estos votos convierte a la Corte en un órgano partidista, en el cual cada uno de sus integrantes está más preocupado por defender su propia teoría de la interpretación, más que por una solución colectiva y consensuada de las cuestiones y casos que el tribunal debe decidir (Pasquino, 2016: 40).

En efecto, la neutralidad del tribunal se ve afectada por el uso y abuso de los votos disidentes en las sentencias porque implica "personalizar» sus decisiones al darle más importancia a los votos y argumentos de cada ministro en lugar de enfocarse en la decisión de la institución y el rol que la misma juega en el sistema político.

Adicionalmente, no existen antecedentes acerca del grado de desarrollo que tiene la deliberación en sentido estricto en el Tribunal Constitucional chileno. Sobre el particular, las actas de Salas y del Pleno publicadas por el Tribunal no arrojan evidencia alguna. Sin embargo, existen ciertos factores que inducen a pensar que la deliberación secreta que tiene lugar entre los ministros es breve, y que en consecuencia no existiría deliberación en sentido estricto. El primero de dichos factores es la existencia de límites temporales breves para dictar sentencia (considerando la actual carga de trabajo del Tribunal), y en particular de plazos perentorios para los controles preventivos de (Constitución Política de la República de Chile, 1980: artículo 93 núm. 3), que desincentivan una deliberación de larga duración que permita alcanzar un acuerdo amplio entre los ministros. Como otros posibles factores podemos enumerar la excesiva y creciente carga de trabajo del Tribunal (particularmente el explosivo aumento de causas por requerimiento de inaplicabilidad por inconstitucionalidad), y la falta de más personal idóneo para asistir a los ministros en sus tareas. Sin embargo, el hecho de que existan causas razonables para el problema no justifica abandonar la búsqueda de una solución para el mismo.

En consecuencia, en un escenario normativo en que hay votos nominales (esto es, en que es público el nombre del ministro votante), de publicidad de concurrencias y disidencias, en que existe una tendencia al uso intensivo de votos disidentes, con ministros generalmente de perfil académico o designados unilateralmente por el presidente de la República, y de una práctica y condiciones del tribunal en que es improbable la deliberación en sentido estricto, en el tribunal existen fuertes incentivos para que el contenido de los votos adhiera a posiciones extremas, lo cual inevitablemente afecta la neutralidad de la institución y, en consecuencia, su legitimidad en los términos explicados. 


\section{Conclusiones y algunas ideas para una reforma}

En función de lo expuesto anteriormente, es necesario hacerse cargo de los problemas derivados de la actual regulación. En este contexto, sugiero que mediante una reforma a la Ley Orgánica Constitucional del Tribunal Constitucional se migre hacia un sistema de disensos anónimos, en que la publicidad de las disidencias y concurrencias esté permitida, pero sin señalar qué ministros votaron por la posición mayoritaria o minoritaria. En otras palabras, propongo eliminar el carácter nominal de los votos de los ministros.

Quizás cause extrañeza, atendidos los argumentos de las secciones previas, que mi propuesta no sea eliminar la publicidad de los votos disidentes y concurrentes. A pesar de las evidentes ventajas de un sistema de voto secreto como el existente en el Tribunal Constitucional de Italia, sin duda una prohibición sin matices de la publicidad de votos, disidencias y concurrencias en las sentencias del tribunal implicaría un cambio demasiado radical para la cultura jurídica chilena, acostumbrada a la publicidad de las disidencias y concurrencias en las sentencias en virtud de las reglas sobre el particular aplicables a los tribunales colegiados que pertenecen al Poder Judicial. Además, eliminar totalmente la publicidad de las disidencias es un desafío demasiado frontal a los niveles de transparencia exigibles a un órgano público en un régimen de democracia liberal, y probablemente provocaría suspicacias atendido el principio de publicidad de los actos de los órganos del Estado consagrado en la Carta Fundamental chilena.

Adicionalmente, es difícil de refutar el hecho que «la mayoría de los académicos, y los jueces mismos, concuerdan en que un sistema que permite la publicación de los disensos mejora la calidad del voto mayoritario» (Kelemen, 2013: 1.364). Así las cosas, un sistema de disenso anónimo permitiría retener esta ventaja de la publicación de los votos disidentes (porque la justificación de dichos votos sí sería pública), y al mismo tiempo evitar las consecuencias negativas del carácter nominal del voto.

En este contexto, sostengo que un sistema de disensos anónimos es más idóneo para hacerse cargo de las principales desventajas de la regulación actual en materia de publicidad de votos en las sentencias del Tribunal Constitucional chileno, a saber, los fuertes incentivos existentes para una excesiva «personalización» de las decisiones del tribunal y para la defensa de posiciones extremas por parte de sus miembros, en cuanto favorecería un aumento en la neutralidad de dicho órgano. Además, al evitar el carácter nominal del voto se contribuye a impedir que el tribunal se convierta en un Congreso a escala o un microparlamento.

No obstante, además de la implementación de un sistema de disenso anónimo en las sentencias del tribunal, fortalecer su legitimidad supone crear un marco institucional que favorezca una deliberación en sentido estricto previa a la dictación de las sentencias. En efecto:

La deliberación «cara a cara» es una condición necesaria que le permite a la Corte alcanzar un compromiso entre las posturas de los magistrados. Si esta no tiene lugar, o si se desarrolla en un periodo muy corto, como en el Consejo francés, la votación tomará 
el lugar de la deliberación, con lo cual la Corte se transformará en un microparlamento, donde los votos más que los argumentos son el criterio determinante para alcanzar la decisión final (Pasquino, 2016: 39-40).

Desde luego, para que tal forma de deliberación sea posible es indispensable no solo una reforma legal, sino también que los ministros del tribunal puedan contar con el tiempo y los recursos humanos y materiales necesarios para ello.

Finalmente, fortalecer la legitimidad del tribunal requeriría modificar el procedimiento de designación de sus miembros. En este sentido:

La presencia simultánea de diferentes inclinaciones políticas, así como de una sensibilidad tendiente a encontrar un «terreno intermedio» por medio de la deliberación, permitiría que las decisiones políticas de las Cortes respondan menos a intereses partidistas en comparación con las determinaciones que toma a una mayoría elegida en el Parlamento» (Pasquino, 2016: 39).

Sin embargo, la forma en que este objetivo puede alcanzarse excede, sin duda, el alcance de este trabajo.

\section{Referencias}

Atria, Fernando (2016). La forma del derecho. Madrid: Marcial Pons.

Carroll, Royce y Lydia Tiede (2011). "Judicial Behavior on the Chilean Constitutional Tribunal». Journal of Empirical Legal Studies, 8 (4): 856-877.

Kelemen, Katalin (2013). «Dissenting Opinions in Constitutional Courts». German Law Journal, 14 (8): 1.345-1.371.

Kelsen, Hans (1949). General Theory of Law and State. Cambridge: Harvard University Press.

-. (2008). Pure Theory of Law. Nueva Jersey: The Lawbook Exchange.

Kelsen, Hans y Carl Schmitt (2009). La polémica Schmitt/Kelsen sobre la justicia constitucional: El defensor de la Constitución versus ¿Quién debe ser el defensor de la Constitución? Madrid: Tecnos.

Montesquieu (2012). Del espíritu de las leyes. Madrid: Alianza.

PARdow, Diego y Sergio Verdugo (2015). «El Tribunal Constitucional chileno y la reforma de 2005: Un enroque entre jueces de carrera y académicos». Revista de Derecho (Valdivia), 28 (1): 123-144. DOI: 10.4067/So718-09502015000100006.

PAsquino, Pasquale (2015). «E pluribus unum: Disclosed and undisclosed vote in Constitutional/Supreme Courts». En Jon Elster (editor), Secrecy and Publicity in Votes and Debates (pp. 196-208). Nueva York: Cambridge University Press.

-. (2016). «¿Cómo deciden las Cortes Constitucionales?». Precedente. Revista Jurídica, 9: 9-44. DOI: $10.18046 /$ prec.v9.2424.

-. (2018). "A Political Theory of Constitutional Democracy: On Legitimacy of Constitutional Courts in Stable Liberal Democracies». En Thomas Christiano, Ingrid 
Creppell y Jack Knight (editores), Morality, Governance, and Social Institutions. Reflections on Russell Hardin (pp. 197-232). Cham: Palgrave Macmillan.

Verdugo, Sergio (2011). «Aportes del modelo de disidencias judiciales al sistema político. Pluralismo judicial y debate democrático». Revista de Derecho Universidad Católica del Norte, 18 (2): 217-272. DOI: 10.4067/S0718-97532011000200009.

VInX, Lars (2015). The Guardian of the Constitution. Hans Kelsen and Carl Schmitt on the Limits of Constitutional Law. Cambridge: Cambridge University Press.

\section{Sobre el autor}

Edison Patricio Orellana Ramos es Licenciado en Ciencias Jurídicas y Sociales de la Universidad de Chile (2012) y Master of Arts (M.A) in Politics de la New York University (2018). Su correo electrónico es edisonorellanaramos@gmail.com. ID https:// orcid.org/0000-0002-6307-6585. 
